\title{
Iron-deficiency anemia as a risk factor for acute lower respiratory tract infections in children younger than 5 years Ola G. Behairy ${ }^{\mathrm{a}}$, Osama I. Mohammad ${ }^{\mathrm{b}}$, Osama S. Elshaer ${ }^{\mathrm{C}}$
}

\author{
Background Acute lower respiratory tract infection (ALRTI) \\ is an important cause of morbidity in the developed world and \\ both morbidity and mortality in the developing world. \\ Moreover, iron-deficiency anemia (IDA) is a major health \\ problem in children.
}

Aim The aim was to evaluate IDA as a risk factor for ALRTIs in
children.

Participants and methods A total of 200 children were enrolled in this study, and they were divided into two groups: group I included 100 children with lower respiratory tract infections and group II included 100 apparently healthy children matched for age and sex as a control group. All enrolled children were subjected to history taking with stress on recurrent chest infection, clinical examination, and chest radiographs. Complete blood counting was done with measures of serum iron, serum ferritin levels, and total ironbinding capacity.

Results Anemia was found in $74 \%$ of cases and $38 \%$ of controls. IDA was present in $60 \%$ of cases and $24 \%$ of controls. There was a statistically significant increased incidence of anemia [odds ratio (OR) was 4.64] and presence of IDA (OR was 4.75) in group I compared with group II.

\section{Introduction}

Acute lower respiratory tract infections (ALRTIs) in children younger than 5 years are the main cause of childhood morbidity and mortality worldwide and represent almost $60 \%$ of hospitalizations owing to infant infectious disease [1]. Bronchitis, bronchiolitis, and pneumonia alone or in combinations constitute forms of lower respiratory tract infections (LRTIs) [2]. The chance to develop LRTI may be enhanced by nutritional factors such as zinc, iron, vitamin $A$ and others, which are closely related to the body's resistance to infection. Decrease in such nutrients may be a risk factor for development of infection. However, there are controversies regarding the role of nutrients especially iron in respiratory tract infections in childhood [3]. On the contrary, anemia is a major public health problem that can occur at any stage of the life and is more prevalent in pregnant women and young children [4]. Anemia associated with acute infections occurs more commonly in children as it exerts adverse effects on immune response and alters metabolism and growth of pathogens [5]. Regarding nutritional causes of anemias, iron-deficiency anemia (IDA) is the commonest [6]. IDA in children occurs most frequently between the age of 6 months and 3 years, which is the same period of repeated respiratory tract infections [7]. Whatever the etiology of anemia, the
Regarding recurrent chest infections, there was a statistically significant increased incidence in children with anemia compared with those without anemia (OR was 27.60) and between non-IDA and IDA, as it was significantly higher in children with IDA (OR was 10.26).

Conclusion Children with IDA were found to be four times more susceptible to ALRTI and ten times more susceptible to recurrent chest infections when compared with children without anemia.

Egypt J Bronchol 2018 12:352-357

(C) 2018 Egyptian Journal of Bronchology

Egyptian Journal of Bronchology 2018 12:352-357

Keywords: acute lower respiratory tract infections, iron-deficiency anemia, recurrent chest infection, serum ferritin, serum iron

Departments of, ${ }^{\text {aPediatrics, }}{ }^{\mathrm{b}} \mathrm{Chest},{ }^{\mathrm{c}} \mathrm{Clinical}$ and Chemical Pathology, Faculty of Medicine, Benha University, Benha, Egypt

Correspondence to Osama I. Mohammad, MD, Department of Chest, Faculty of Medicine, Benha University, Benha, Qualuibiya, Egypt. Tel: +201273646430;

e-mail: osama.thorax@yahoo.com

Received 30 July 2017 Accepted 2 September 2017

relation between low hemoglobin $(\mathrm{Hb})$ level and ALRTIs has not been fully investigated, and only a few reports are available evaluating this subject [8].

We aimed to evaluate IDA as a risk factor for ALRTIs in children.

\section{Participants and methods}

This was a cross-sectional case-control study that was conducted at Pediatrics Department, Benha University hospitals in the period from May 2016 to May 2017. Overall, two groups of children were enrolled: group I (cases) included 100 infants and children aged 6 months to 5 years and all had LRTIs, whereas group II included 100 apparently healthy infants and children ( $<5$ years) without any respiratory problems as a control group, from the attendance of vaccination/well baby clinic.

\section{Inclusion criteria}

The inclusion criteria for cases were children aged between 6 months and 5 years with a diagnosis of

This is an open access journal, and articles are distributed under the terms of the Creative Commons Attribution-NonCommercial-ShareAlike 4.0 License, which allows others to remix, tweak, and build upon the work non-commercially, as long as appropriate credit is given and the new creations are licensed under the identical terms. 
ALRTI by WHO criteria according to Christi et al. [9] (fever, cough, increase respiratory rate for age, chest indrawing, and rhonchi or crepitation on auscultation).

\section{Exclusion criteria}

The exclusion criteria included presence of any other known risk factors for LRTIs, including prematurity, congenital chest wall malformations, passive smoking, intake of iron supplements, and severe systemic illness, e.g. malnutrition, congenital heart disease, and tuberculosis.

The study gained the approval of local ethical committee of Benha University. Informed written consent was obtained from the parents or caregivers of enrolled children after explanation of the study, and the study was conducted according to principles of Helsinki Declaration [10].

\section{Methods}

The enrolled children were subjected to full history taking with special attention to symptoms of ALRTI like fever, lethargy, poor feeding, cough, wheeze, tachypnea, chest in-drawing, grunting, history of recurrent chest infection [to diagnose recurrent infection (RI) at least one of the following criteria has to be present: (a) more than $6 \mathrm{RI}$ per annum, (b) more than $1 \mathrm{RI}$ per month involving the upper airways from September to April, and (c) more than $3 \mathrm{RI}$ per annum involving the lower airways] [11] and vaccination history. Detailed physical examination was performed including weight and height, which were recorded for all children to assess the nutritional status, as well as chest, cardiac, and abdominal examination. Children were classified according to the degree of respiratory distress $(\mathrm{RD})$ into the following: grade I (mild distress): tachypnea, working ala nasi, and tachycardia; grade II (moderate distress): chest retraction 'in-drawing' (e.g. subcostal and intercostal); grade III (severe distress): grunting, which occurs because of severe hypoxemia and indicates alveolar lesion; and grade IV: cyanosis and disturbed consciousness [12]. Chest radiographs were done for all children. Laboratory investigations were done for all children by taking venous blood samples $(5 \mathrm{ml})$ that were obtained under complete aseptic technique. Each sample was divided into two parts: one part $(2 \mathrm{ml})$ was put into an EDTA tube for complete blood count analyzed by Sysmex KX-21N (Sysmex Corporation, New York, USA) and peripheral blood smear (Hb level $<11 \mathrm{~g} \%$ was considered low) [13]. The other part ( $3 \mathrm{ml})$ was put into plain vacutainers for serum iron and total ironbinding capacity (TIBC), which was detected using Biosystem BTS-350 (Biosystem S.A., Barcelona,
Spain) by kits (Spectrum Diagnostics iron and TIBC reagent set). Reference ranges for serum iron were $40-100 \mu \mathrm{g} / \mathrm{dl}$ for infants and $50-120 \mu \mathrm{g} / \mathrm{dl}$ for children. For TIBC, reference ranges were $100-140 \mu \mathrm{g} / \mathrm{dl}$ for infants and $250-400 \mu \mathrm{g} / \mathrm{dl}$ for children [14]. Serum ferritin was detected using Biosystem BTS-350 (Spectrum Diagnostic Ferritin Turbi Latex, Biosystems S.A., Barcelona, Spain). Transferrin saturation was calculated using the following formula: transferrin saturation=iron level/TIBC $\times 100$ (normal value $=20-45 \%)$ [15]. C-reactive protein level more than $6 \mathrm{mg} / \mathrm{dl}$ was considered positive. As infection can affect iron panel by increasing serum ferritin level (usually by $>50 \mu \mathrm{g} / 1$ if no iron deficiency) and decreasing serum iron level and TIBC, so IDA was diagnosed in patients with LRTI when at least three of the following parameters were present [16]: (a) blood smear showing hypochromia and microcytosis; (b) low mean corpuscular volume $(\mathrm{MCV})$ if the cells are smaller than normal (under $75 \mathrm{fl}$ ); (c) red cell distribution width greater than 14.5; and (d) Mentzer index greater than 13.5 (the Mentzer index was calculated using the following formula: Mentzer index=MCV/red blood cell count), and (e) transferrin saturation less than 10. In the control group, IDA was diagnosed when serum ferritin level was less than $10 \mathrm{ng} / \mathrm{ml}$ [15], or when serum iron level was lower than $50 \mu \mathrm{g} / \mathrm{dl}$ and serum TIBC was higher than $400 \mu \mathrm{g} / \mathrm{dl}[14]$.

\section{Statistical analysis}

Data were tabulated, coded, and analyzed using the STATA version 11 (STATA Corporation, College Station, Texas, USA). Two types of statistics were performed: descriptive statistics included percentage, mean, and SD, and analytic statistics included independent samples Student's $t$-test, which is used to compare two mean, and $\chi^{2}$, which is used for comparison between categorical variables, Fischer's exact test, confidence interval $(\mathrm{CI})$, and the odds ratio (OR). For all analyses, the level of significance was set at $P$ value of less than 0.05 .

\section{Results}

The study was conducted on 200 children and they were divided into two groups: group I (cases) included 100 infants and children aged 6 months to 5 years with mean $28.32 \pm 16.34$ months; they were 72 males and 28 females. Group II included 100 apparently healthy infants and children with mean age $28.28 \pm 16.59$ months; they were 74 males and 26 females. There was no statistically significant difference between cases and control group regarding sociodemographic characteristics (Table 1). Clinical 
features of cases in group I were cough, fever, poor feeding, and fast breathing, which were the main symptoms observed in 100, 98, 62, and 58\%, respectively. RD grade I was found in $24 \%$ of cases, $\mathrm{RD}$ grade II in $10 \%, \mathrm{RD}$ grade III in $10 \%$, and $\mathrm{RD}$ grade IV in $14 \%$ of patients. Auscultatory chest findings revealed crepitations in $30 \%$, rhonchi in $24 \%$, and both crepitations and rhonchi in $26 \%$ of patients. Constitutional symptoms like diarrhea and vomiting was observed in 18 and 28\%, respectively. Convulsion, disturbed conscious level, and positive CRP were present in 20,12 , and $80 \%$, respectively.

Classification of cases regarding diagnosis based on WHO guidelines and radiological evidence [17] was as follows in group I (cases): lobar pneumonia was present in $12 \%$, bronchopneumonia in $34 \%$, hyperinflated lungs suggestive of bronchiolitis in 24\%, and 30\% had acute bronchitis (normal chest radiography).

There was statistically significant decrease in all laboratory parameters of anemia $(\mathrm{Hb}$, red blood cells count, MCV, mean corpuscular hemoglobin, mean corpuscular hemoglobin concentration, serum iron, serum ferritin, and transferrin saturation) in group I, except for red blood cell distribution width percentage and TIBC, which were significantly increased (Table 2). There was statistically significant increased incidence of anemia in group I compared with group II, with OR of 4.64 and 95\% CI: $1.99-10.80$ ), as the study show that $74(74 \%)$ of 100 cases and 38 (38\%) of 100 controls were anemic, and we found that $60(60 \%)$ of cases and $24(24 \%)$ of controls had IDA, with OR of 4.75 and $95 \%$ CI: 2.02-11.14 (Table 3).

There was statistical significant difference between anemic and nonanemic cases in both groups regarding recurrent chest infection, as it was higher in anemic children with OR of 27.60 and 95\% CI: 9.52-79.95, and between non-IDA and IDA, as it was higher in IDA, with OR of 10.26 and 95\% CI: 3.91-26.81. There were 108 of 200 infants and children who had a history of recurrent chest infection, 94 (87.04\%) were anemic, $14(12.96 \%)$ were nonanemic, 70 (64.8\%) were IDA, and 38 (35.19\%) were non-IDA (Table 4). When comparing anemic cases ( 74 cases) with anemic controls (38 cases), there was statistically significant difference regarding $\mathrm{Hb}$ level mean $(8.44 \pm 1.23$ and $9.13 \pm 0.86$, respectively). However, there was no statistical significant difference between anemic

Table 1 Sociodemographic characteristics of studied children

\begin{tabular}{lccc}
\hline Variables & \multicolumn{2}{c}{ Groups [n (\%)] } & Tests \\
\cline { 2 - 3 } & Group I $(n=100)$ & Group II $(n=100)$ & \\
\hline Sex & $28(28)$ & $26(26)$ & \multirow{2}{*}{0.75} \\
$\quad$ Females & $72(72)$ & $74(74)$ & \\
$\quad$ Males & & $28.28 \pm 16.59(8-60)$ & $t=0.02$ \\
Age (months) & $28.32 \pm 16.34(7-60)$ & $64(64)$ & 0.99 \\
$\quad$ Mean \pm SD (range) & $66(66)$ & $36(36)$ & $\chi^{2}=0.09$ \\
Residence & $34(34)$ & & 0.77 \\
$\quad$ Rural & & & \\
$\quad$ Urban & & & \\
\hline
\end{tabular}

Table 2 Laboratory parameters of anemia in group I (cases) and group II (controls)

\begin{tabular}{|c|c|c|c|c|}
\hline \multirow[t]{2}{*}{ Variables } & \multicolumn{2}{|c|}{ Groups [mean \pm SD (range)] } & \multirow[t]{2}{*}{$t$-Test } & \multirow[t]{2}{*}{$P$} \\
\hline & Group I (cases) $(n=100)$ & Group II (controls) $(n=100)$ & & \\
\hline $\mathrm{Hb}(\mathrm{g} / \mathrm{dl})$ & $9.45 \pm 2.03(6-13.5)$ & $11.26 \pm 1.92(7.9-14.5)$ & 6.48 & $<0.001(\mathrm{HS})^{*}$ \\
\hline RBCs (million/ml) & $3.15 \pm 0.66(2-5)$ & $3.51 \pm 0.6(2.5-5)$ & 4.04 & $<0.001$ (HS) \\
\hline MCV (fl) & $75.26 \pm 7.04(60-90)$ & $82.48 \pm 6.42(70-96)$ & 7.58 & $<0.001(\mathrm{HS})^{\star}$ \\
\hline $\mathrm{MCH}(\mathrm{pg})$ & $26.52 \pm 3.16(20-33)$ & $28.52 \pm 2.74(22-33)$ & 4.78 & $<0.001$ (HS) \\
\hline $\mathrm{MCHC}(\mathrm{g} / \mathrm{dl})$ & $28.7 \pm 4.59(20-35)$ & $31.64 \pm 2.24(26-35)$ & 5.76 & $<0.001(\mathrm{HS})^{*}$ \\
\hline RDW-CV (\% age) & $17.62 \pm 5.37(11-35)$ & $14.72 \pm 4.46(11-32)$ & 4.15 & $<0.001(\mathrm{HS})^{*}$ \\
\hline Serum iron $(\mu \mathrm{g} / \mathrm{dl})$ & $55.08 \pm 35.27(10-150)$ & $70.3 \pm 27.47(15-110)$ & 3.40 & $<0.001(\mathrm{HS})$ \\
\hline Serum ferritin (ng/ml) & $34.47 \pm 41.51(1.5-130)$ & $57.13 \pm 37.62(3.5-120)$ & 4.04 & $<0.001(\mathrm{HS})$ \\
\hline $\operatorname{TIBC}(\mu \mathrm{g} / \mathrm{dl})$ & $454.4 \pm 152.1(200-700)$ & $358.4 \pm 128.3(200-750)$ & 4.82 & $<0.001(\mathrm{~S})^{*}$ \\
\hline Transferrin saturation (\%) & $15.82 \pm 13.9(2-47)$ & $22.82 \pm 11.36(2-40)$ & 3.90 & $<0.001(\mathrm{HS})$ \\
\hline
\end{tabular}

$\mathrm{Hb}$, hemoglobin; $\mathrm{HS}$, highly significant; $\mathrm{MCH}$, mean corpuscular hemoglobin; $\mathrm{MCHC}$, mean corpuscular hemoglobin concentration; MCV, mean corpuscular volume; RBC, red blood cells; RDW, red blood cell distribution width; S, significant; TIBC, total iron-binding capacity;

*Significant difference. 
cases and anemic controls regarding other laboratory parameters of anemia (serum iron, serum ferritin, $\mathrm{TIBC}$, and transferrin saturation).

The grades of $\mathrm{RD}$ increase as the percentage of cases having anemia or IDA increases, as we found that $58.3 \%$ of cases presented by RD grade I had anemia and $50 \%$ had IDA; among those with RD grade II, $60 \%$ had anemia and 60\% had IDA; among those with RD grade III, 80\% had anemia and 80\% had IDA; and $85 \%$ presented by RD grade IV had anemia and $71.43 \%$ had IDA. However, there was no statistically significant difference between different grades of $\mathrm{RD}$ among case group regarding presence of both anemia and IDA (Table 5).

\section{Discussion}

In the present study, there was a statistically significant increased incidence of anemia in group I compared with group II, with OR of 4.64 and 95\% CI:
1.99-10.80, and IDA, with OR of 4.75 and $95 \%$ CI: 2.02-11.14. These results were in agreement with Roma et al. [18] as their study was done on 100 cases with ALRTI and 100 controls; they found that $72 \%$ of cases and $34 \%$ of controls were anemic, with an OR of 4.99 and 95\% CI: 2.73-9.1. Among the case and control groups, 62 (86\%) and 21 (63\%) had IDA, respectively. They concluded that children with anemia (mainly IDA) when compared with control group were found to be 4.99 times more susceptible to ALRTI, and early management of anemia might prevent the development of ALRTI.

Sheikh et al. [19] found that anemia was present in 71 (64.5\%) cases with ALRTI in the study group and in 31 (28.2\%) in the control group. Patients with anemic were found to be 4.6 times more susceptible to ALRTI in their study (OR was 4.63, $P<0.01$ ) and IDA was found in $78.9 \%$ of total anemic cases in the study group. They concluded that anemia, especially IDA, was significantly found in children with ALRTI, and

Table 3 Comparison between studied groups regarding presence of anemia and iron-deficiency anemia

\begin{tabular}{|c|c|c|c|c|c|}
\hline \multirow[t]{2}{*}{ Variables } & \multicolumn{2}{|c|}{ Groups [n (\%)] } & \multirow[t]{2}{*}{$\chi^{2}$ test } & \multirow[t]{2}{*}{$P$} & \multirow[t]{2}{*}{ OR $(95 \% \mathrm{Cl})$} \\
\hline & Group I $(N=100)$ & Group II $(N=100)$ & & & \\
\hline \multicolumn{6}{|l|}{ Anemia } \\
\hline Anemic & $74(74.0)$ & $38(38.0)$ & 26.30 & $<0.001(\mathrm{HS})^{*}$ & $4.64(2.44-8.89)$ \\
\hline Nonanemic & $26(26.0)$ & $62(62.0)$ & & & \\
\hline \multicolumn{6}{|l|}{ IDA } \\
\hline Present & $60(60.0)$ & $24(24.0)$ & 26.60 & $<0.001(\mathrm{HS})^{\star}$ & $4.75(2.48-9.17)$ \\
\hline Absent & $40(40.0)$ & $76(76.0)$ & & & \\
\hline
\end{tabular}

$\mathrm{Cl}$, confidence interval; HS, highly significant; IDA, iron-deficiency anemia; OR, odds ratio; ${ }^{*}$ Significant difference.

Table 4 Comparison between anemic and nonanemic cases in all study groups regarding presence of recurrent chest infection

\begin{tabular}{|c|c|c|c|c|c|}
\hline \multirow[t]{2}{*}{ Variables } & \multicolumn{2}{|c|}{ Groups [n (\%)] } & \multirow[b]{2}{*}{$\chi^{2}$ test } & \multirow[t]{2}{*}{$P$} & \multirow[t]{2}{*}{ OR $(95 \% \mathrm{Cl})$} \\
\hline & Negative $(n=92)$ & Positive $(n=108)$ & & & \\
\hline \multicolumn{6}{|l|}{ Anemia } \\
\hline Yes & $18(19.57)$ & $94(87.04)$ & 91.79 & $<0.001(\mathrm{HS})^{*}$ & $27.60(12.15-63.88)$ \\
\hline No & $74(80.43)$ & $14(12.96)$ & & & \\
\hline \multicolumn{6}{|l|}{ IDA } \\
\hline Yes & $14(15.22)$ & $70(64.81)$ & 50.17 & $<0.001(\mathrm{HS})^{*}$ & $10.26(4.91-22.08)$ \\
\hline No & 78 (84.78) & 38 (35.19) & & & \\
\hline
\end{tabular}

$\mathrm{Cl}$, confidence interval; HS, highly significant; IDA, iron-deficiency anemia; OR, odds ratio; ${ }^{*}$ Significant difference.

Table 5 Respiratory distress among patients regarding presence of anemia

\begin{tabular}{lcccc}
\hline Variables & \multicolumn{4}{c}{ RD grades [n (\%)] } \\
\cline { 2 - 4 } & RD grade I $(n=24)$ & RD grade II $(n=10)$ & RD grade III $(n=10)$ & RD grade IV $(n=14)$ \\
\hline Anemia & & & & \\
Yes & $14(58.3)$ & $6(60)$ & $8(80)$ & $12(85.71)$ \\
No & $10(41.6)$ & $4(40)$ & $2(20)$ & $2(14.29)$ \\
IDA & $12(50)$ & $6(60)$ & $8(80)$ & $10(71.43)$ \\
Yes & $12(50)$ & $4(40)$ & $2(20)$ & $4(28.57)$ \\
No & & & & 0.27 \\
\hline
\end{tabular}

IDA, iron-deficiency anemia; RD, respiratory distress; ${ }^{\mathrm{a}}$ Obtained by Fisher's exact test. 
these children were found to be 4.6 times more susceptible to ALRTI. This may be explained by the fact that the normal function of $\mathrm{Hb}$ facilitates oxygen and carbon dioxide transport, and it carries and inactivates nitric oxide and also plays the role of buffer. Therefore, quantitative and/or qualitative reduction in $\mathrm{Hb}$ level may adversely affect its normal functions. Probably it may be the reason that low $\mathrm{Hb}$ level is found to be a serious risk factor for developing ALRTIs [20].

In the present study, there was statistical significant difference between anemic cases and anemic control as regarding $\mathrm{Hb}$ level as it was lower in anemic cases. These results were in agreement with Rashad et al. [21] who found that there was statistical significant difference between anemic controls and patients with anemia regarding $\mathrm{Hb}$ levels, as it was lower in patients with anemia (mean \pm SD: $10.1 \pm 0.60$ and 9.5 \pm 1.1 , respectively) $(P=0.007)$. Moreover, our results were in agreement with the study by Abdel-Maksoud et al. [22] that was conducted in Pediatric Department, Al-Azhar University Hospital (Damietta), and it included 300 children divided into two equal groups according to presence or absence of pneumonia. The study found significant difference between cases and controls, as mean $\mathrm{Hb}$ level was 11.4 for cases and 12 for controls.

In the present study regarding the history of recurrent chest infections, there was a statistical significant difference between anemic and nonanemic cases in both groups regarding recurrent chest infection, with OR of 27.60 and $95 \% \mathrm{CI}$ : 9.52-79.95, and among nonIDA and IDA, with OR of 10.26 and 95\% CI: 3.91-26.81. These results were in agreement with Rashad et al. [21] who found that history of recurrent chest infection was significantly more common in anemic than in nonanemic children, with CI of $4.88-49.53$, as $63.3 \%$ of anemic children had positive history of recurrent chest infection and $10 \%$ of nonanemic children had positive history of recurrent chest infection. They concluded that anemia, especially IDA, is a community problem in Egypt and children with anemia are about four times more susceptible to developing pneumonia compared with the nonanemic children, and IDA is predominating.

Maurad et al. [23] found that there was statistical significant difference between both anemic group and hospitalized cases when compared with nonanemic group and healthy controls regarding history of recurrent chest infections, as it was higher in children with anemic (37.5\%) when compared with nonanemic children (14.5\%). They concluded that when anemia was present (mainly IDA), children were two times more susceptible to have LRTI when compared with the control group.

Regarding RD, there was no statistically significant difference between different grades of $\mathrm{RD}$ among case group regarding the presence of both anemia and IDA; however, the grade of $\mathrm{RD}$ increases as the percentage of cases having anemia or IDA increases. The relation between IDA and severity of degree of RD may be explained by the fact that iron deficiency impairs cell-mediated immunity; therefore, iron appears to participate directly in immunity and lung injury [24]. The current study shows that anemia, especially IDA, is still a community problem in Egyptian children. In addition, it provides a statistically significant positive association between anemia, predominantly IDA, and ALRTI.

Hence, early detection and timely correction of anemia may be helpful for prevention of ALRTI and decrease recurrence of chest infection in children in this age group.

Limitation of this study was small number of children included, so large-scale studies may be needed to confirm the results of our study.

\section{Conclusion}

Children with anemia and those with IDA were found to be more susceptible to ALRTI and also more susceptible to recurrent chest infections when compared with children without IDA.

\section{Limitation of study}

Our study may be limited by small number of cases enrolled in it.

\section{Financial support and sponsorship \\ Nil.}

\section{Conflicts of interest}

There are no conflicts of interest.

\section{References}

1 Peiris JS, Tang WH, Chan KH, Khong PL, Guan Y, Lau YL, Chiu SS. Children with respiratory disease associated with metapneumo virus in Hong Kong. Emerg Infect Dis 2009; 9:628-633.

2 Barson WG, Kaplan SL, Torchia MM. Epidemiology, pathogenesis, and etiology of pneumonia in children. Available at: http://www.Up To Date [3 November 2016]. 
3 Zuo XF, Li JX, Zhou WD. The nutrient status of Chinese infants with pneumonia. Biomed Res 2014; 25: 317-320.

4 Bruno de B, McLean E, Egli I, Cogswell M. Worldwide prevalence of anaemia 1993-2005: WHO global database on anemias. Geneva: World Health Organization; 2008.

5 Ramakrishnan K, Harish PS. Hemoglobin level as a risk factor for lower respiratory tract infection. Indian J Pediatr 2006; 73:881-883.

6 Lerner NB, Sills R. Iron deficiency anemia. In: Kliegmen RM, Stanton BF St, Geme JW, Schor NF, Behrman RE, editors. Nelson textbook of pediatrics. 19th ed. Philadelphia: Elsevier; 2011. 1655-1658.

7 Bont L, Heijnen C, Kavelaars A, van Aalderen W, Brus F, Draaisma J, et al. Local interferon-levels during respiratory syncytial virus lower respiratory tract infection are associated with disease severity. J Infect Dis 2009; 184:355-358.

8 Carroll K, Wu P, Gebretsadik T, Griffin M, Dupont W, Mitchel T, Hartert T. The severity-dependent relationship of infant bronchiolitis on the risk and morbidity of early childhood asthma. J Allergy Clin Immunol 2009; 123:1055-1061.

9 Christi MJ, Tebruegge M, LaVincente S, Graham SM, Duke T. Pneumonia in severely malnourished children in developing countries-mortality risk, etiology and validity of WHO clinical sings: a systemic review. Trop Med Int Health 2009; 14:1173-1189.

10 World Medical Association. Declaration of Helsinki-Ethical Principles for Medical Research Involving Human Subjects. Seoul, South Korea: the 59th WMA General Assembly; 2008.

11 Gruppo di Studio di ImmunologiadellaSocietàltaliana di Pediatria. Le infezioniricorrentinel bambino: definizioneedapproccio diagnostic. Rivista di Immunolgia e Allergologia Pediatrica 1988; 2:127-134.

12 Paetzel M. Respiratory distress syndrome (grade 1-4) of the premature and newborn (IRDS). PedRad (serial online). Available at: http://www PedRad.info/?search $=20021110223558$. [Last accessed on 2017 May 15].

13 Park K. Nutrition and health. Park's text book of preventive and social medicine. 21st ed. Premnagar, Jabalpur, (M.P.), India: Banarasidas Bhanot Publishers Publication; 2011. pp. 561-617.
14 Burtis CA, Edward RA. Principles of colorimetric determination of unsaturated iron binding capacity in serum. In: Burtis CA, Edward RA, David EB, editors. Tietz textbook of clinical chemistry. 4th ed. Philadelphia: Elsevier Saunders; 2006. 2195-2197.

15 McPherson RA, Pincus MR. Iron deficiency anemia: diagnosis and management. In: McPherson RA, Pincus MR, editors. Henry's clinical diagnosis and management laboratory methods. 21st ed. Philadelphia: WB Saunders; 2007. 455-482.

16 Sipahi T, Köksal T, Tavil B, Akar N. The effects of acute infection on hematological parameters. Pediatr Hematol Oncol 2004; 21:513-520.

17 Cherian T, Mulholland EK, Carlin JB, Ostensen H, Amin R, Campo M, et al. The WHO Radiology Working Group. Standardized interpretation of paediatric chest radiographs for the diagnosis of pneumonia in epidemiological studies. Bull World Health Organ 2005; 83:353-359.

18 Roma KM, Gupta V, Ahmad S, Ranhotra S, Issrani R, Prabhu N. Assessment of anemia as a risk factor for acute lower respiratory tract infections in children: a case-control study. Int J Clin Pediatr 2015; 4:149-153.

19 Sheikh HQ, Ashraf M, Wani JG, Ahmed J. Low hemoglobin level a risk factor for acute lower respiratory tract infections (ALRTI) in Children. J Clin Diagn Res 2014; 8:1-3.

20 Ganong WF. 'Gas transport between the lungs and tissues'. Review of medical physiology. 22nd ed. New York: McGraw-Hill; 2005 666-669.

21 Rashad MM, Fayed SM, El-Hag AM. Iron-deficiency anemia as a risk factor for pneumonia in children. Benha Med J 2015; 32:96-100.

22 Abdel-Maksoud HM, Hasan AK, Mohamed Ahmed Helwa MA. Evaluation of iron deficiency anemia as a predisposing factor in the occurrence of pneumonia in children. Trends Med Res 2016; 11:69-75.

23 Maurad S, Rajab M, Alameddine A, Fares M, Ziade F, AbdouMerhi B. Hemoglobin level as risk factor for lower respiratory tract infections in Lebanese children. North Am J Med Sci 2010; 2:461-466.

24 Ghio AJ. Disruption of iron homeostasis and lung disease. Biochim Biophys Acta 2009; 1790:731-739. 